\title{
O OBJETO EM CAUSA NA CURA
}

Christian Hoffmann

Psicanalista, professor de Psicopatologia Clínica na Universidade de Paris VII.

Tradução: Pedro Henrique Bernardes Rondon
RESUMO: A repetição é sinônimo de perda e, conseqüentemente, de fracasso do gozo. Desse fracasso pode ser deduzido o objeto do desejo. O tratamento analítico visa a produzir esse objeto como causa do desejo.

Palavras-chave: Repetição, fracasso, objeto, final de análise.

ABSTRACT: The object involved in the treatment. Repetition is tantamount to loss, and therefore of jouissance's failure. From that failure the object of wish can be deduced. Analytic therapy aims at bringing about that object as the cause of the wish.

Keywords: Repetition, failure, object, end of analysis.

$\mathrm{M}$

uito já foi dito acerca do objeto a de Lacan. De minha parte, trata-se de distinguir entre: 1) Os objetos a ditos "naturais" que provêm do corpo fragmentado como queda desse corpo; 2) Os equivalentes na cultura, como produção e como sublimação; 3) O analista como objeto a, isto é, como causa de uma análise. O que faz presumir que ele tenha levantado o desconhecimento do objeto a "natural". O que haverá a dizer? Apenas que o sujeito, o analisante, estava bastante distante na realização de seu desejo para reintegrá-lo à sua causa (LACAN, 1962-63), isto é, à sua falta. É o que tão bem traduz o poema de R. Char que cito aqui: "O poema é o amor realizado do desejo que continuou desejo” (Poèmes en archipel, 2007, p.154).

Vou me prender a um comentário desta última proposição acerca do objeto a na cura. O que vem resultar em falar do manejo do objeto a na cura. Não há muitas dificuldades quanto a apreender o estatuto lógico desse objeto na cura, uma vez que ele se opõe a qualquer tratado das sensações que não distinga entre a sensação e seu objeto. Em suma, ele não é empírico e 
seu estatuto se destaca da própria cura. O objeto a se deduz da cura. Lacan vai dizer mesmo que o objeto a não se verifica senão na cura (LACAN, 1970). Resta a dizer — o que não é pouca coisa: como?

Num texto recente, M. Safouan conclui sua argumentação acerca da elaboração do conceito de objeto a da seguinte maneira: "Eu diria que a teoria do objeto a deu a solução para o problema levantado pela descoberta freudiana do objeto da pulsão, que fez com que sua satisfação se resolva nas repetidas falhas ou numa repetição do fracasso" (SAFOUAN, 2006).

É preciso lembrar que essa descoberta freudiana da pulsão constitui logo de saída sua experiência em direção à satisfação por uma impossibilidade que, para Freud, se origina na primeira experiência de satisfação do bebê no seio da mãe. A redescoberta dessa primeira vez será marcada com o selo do impossível. Por quê?

Para responder a esta pergunta, vou retornar ao "Esquisse d'une psychologie scientifique” [Projeto para uma psicologia científica] (FREUD, 1895/1973), e especialmente a essa Befriedigungserlebnis, no capítulo 11, traduzida como "experiência de satisfação". Prefiro traduzir como Acontecimento de gozo (Erlebnis = um acontecimento marcante, e Befriedigung = saciação, ato de saciar-se).

Esse capítulo do "Projeto" é conhecido por seu desenvolvimento da "ação específica", aquela que não pode ser realizada senão com uma "ajuda exterior", que é despertada pelo grito da criança. Essa ajuda pode ser de alimento ou de presença do Outro. Para Freud, tal acontecimento se torna “a fonte primária de todos os motivos morais".

Essa experiência constitui um "fato de satisfação" que terá as mais importantes conseqüências no desenvolvimento funcional (pensamos no corpo). É a resultante de três fenômenos: uma descarga duradoura se produz; um investimento correspondente à percepção de um objeto se produz no sistema; o anúncio da descarga é recebido no sistema.

Uma "facilitação" (esta questão, que é também a dos traços mnêmicos das lembranças de gozos infantis, vai ser tratada no capítulo VII de $A$ interpretação dos sonhos) forma-se no sistema dessa maneira, e sua reativação pelo desejo ou pela tensão provavelmente vai atingir em primeiro lugar a imagem mnêmica do objeto.

Freud estava convencido de que a alucinação do objeto vai preceder uma decepção inevitável. Isso não deixa de nos fazer lembrar a definição da castração pela desarmonia da experiência do gozo que o sujeito faz entre o gozo buscado e aquele que é encontrado, porque isto não é isso.

Toda a sexualidade infantil vai carregar a marca dessa experiência pulsional do impossível.

A promessa da aurora de R. Gary é uma magnífica ilustração disso: “com o amor materno, a vida te faz na aurora uma promessa que não vai sustentar" (GARY, 1980, p.38). 
Agora é preciso que nos esclareçamos a propósito da repetição dessa falha, sinônimo de insatisfação.

\section{O QUE É A REPETIÇÃO?}

Veremos como Lacan se apropria dessa questão e como lidou com ela a partir de Freud.

A repetição, diz Lacan, fica implicada necessariamente pelo gozo. É porque há uma busca de repetição desse gozo que Freud se lança aos mares do além-doprincípio-de-prazer (o que é uma definição lacaniana do ato como superação).

A experiência e a clínica (o argumento da experiência é raro em Lacan) mostram que a repetição se fundamenta num retorno do gozo e, como Freud o articula, produz-se, dessa mesma repetição, um fracasso, o fracasso do alémdo-princípio-de-prazer.

Isso que já foi identificado por Kierkegaard, quando afirma que aquilo que se repete está em perda em relação àquilo que isso repete. Há um enfraquecimento do gozo na repetição.

Lacan vai situar exatamente nessa repetição a função do objeto perdido, de onde se origina o discurso freudiano.

Aqui vem o que Lacan traz (é assim que ele se exprime a propósito da repetição freudiana e de seu acoplamento lacaniano com o gozo).

Resta-nos debruçar sobre aquilo que ele traz: "o significante se articula portanto para representar um sujeito junto a outro significante. É daí que partimos para dar sentido a essa repetição inaugural, uma vez que ela é repetição que visa o gozo."

É aí que começa o trabalho analítico. A partir daí se encadeia a lógica da cura, a maioria das demandas de análise que podem ser retidas, nos diz M. Safouan em seu artigo sobre "De l'acte analytique" (SAFOUAN, 2001, p.133), se torna um objetivo bastante limitado que consiste naquilo que o analisante chamou de "livrar-se de um certo pacote", isto é, "uma liberação do peso de pesadelo desse gozo”.

Para chegar ao ponto da elaboração do objeto como perda de gozo no próprio lugar de sua busca repetitiva, Lacan vai precisar de cinco anos de seminários, mais “A proposição sobre o passe”, que é a tradução em ato, em outubro de 1967, das conclusões de seu seminário A lógica do fantasma, isto no momento em que se dedica ao Ato analítico. Considero essa Proposição como sendo o resumo, escrito por Lacan, de suas últimas descobertas.

Vou tentar resumi-las (como o fizemos em Lacaniana).

- O objeto da psicanálise (1965-66): a distinção operada por Lacan neste seminário entre os objetos oral e anal que são articulados pela demanda, e os objetos voz e olhar que "formam um todo" com a divisão do sujeito, exige uma teoria do desejo. 
- A lógica do fantasma (1966-67): O fantasma precipita esta teoria do desejo, uma vez que o objeto a é a queda que evidencia que o sujeito não é senão efeito da linguagem. Em suma, se o fantasma por sua sintaxe articula o desejo, sua atuação (guardemos este termo-programa da continuação) é referida ao gozo. Lacan encadeia sobre: não existe ato sexual, diz Lacan, porque há a incomensurabilidade do objeto a à unidade que implica a conjunção de seres de sexo oposto. E esse gozo, na prática, não se aborda senão pelos estragos que são marcados aí a partir do lugar do Outro, que não pode ser colhido senão no corpo. Lacan emprega estes termos muito evocativos de "cicatrizes tegumentares no corpo, pedúnculos que se ramificam por cima de seus orifícios..."

- A proposiçãa acerca do psicanalista da escola (1967) (LACAN, 2001): quando, para Lacan, agora vai se tratar da colocação em ato.

- O ato psicanalítico (1967-68): pode ser indicado no final da análise pela operação de "des-ser" do sujeito-suposto-saber, quando se distribuem os termos do fantasma: o objeto a para o analista e a divisão do sujeito para o analisante. Conhecemos seu efeito de “destituição subjetiva” (cf. Lacan, 1967/2001, p. 273. Lacan dá aí como exemplos de destituição o Le guerrier appliqué de J. Paulhan, e aquele de sua própria posição em seu ensinamento de 1961) sobre o analisante, e o advir da divisão do sujeito no lugar do sujeito-suposto-saber. Esse questionamento de Lacan vai encontrar sua seqüência em seu seminário De um Outro ao outro (1968-69), quando ele vai tentar a articulação do discurso analítico.

Um novo ponto de partida é tomado com a chamada de sua definição do significante como aquilo que representa o sujeito para um outro significante, donde a conseqüência de que o significante não teria o poder de representar a si mesmo, essa chamada é necessária porque mostra que pela repetição e pela articulação do sujeito ao significante, produz-se uma perda na identidade do sujeito que Lacan chama de objeto a.

Na seqüência desse seminário, Lacan vai enunciar pela primeira vez que "não existe relação sexual” (LACAN, 1969, p.216). Ele articula esta afirmação com 0 interdito, o gozo e sua perda, onde agora reconhecemos o objeto a.

Em seguida, para Lacan, vai se tratar de dar a encarnação clínica de sua teoria. Ele considera a clínica como o lugar de captura do Gozo. A clínica lacaniana toma o objeto a como referência. Lacan se pergunta onde está o objeto a nas perversões e na neurose.

O perverso, que ele descreve como sendo um "singular auxiliar de Deus" (idem, p.249), é um defensor da fé que faz o Outro existir consagrando-se a “tapar o furo no outro” (loc. cit.), é bem isso que ele demonstra com o exibicionista que espreita o gozo do Outro fazendo aparecer o olhar no campo do Outro, uma vez que o voyeur interroga aquilo que falta ao Outro, e se encarrega de proporcionar isso. 
Para Lacan resta examinar aquilo que acontece ao objeto a na pulsão sadomasoquista. Acerca deste ponto, ele limita a dor à medida do interdito do gozo, e remete assim o leitor a Sade. Aqui o objeto a é a voz que o masoquista instaura no lugar do Outro, essa voz que é o suporte de sua palavra, que ele está pronto para perder ao tapar o furo no Outro e ao se submeter às suas ordens. O sádico tira do Outro a palavra, impondo-lhe sua voz.

Quanto à neurose, Lacan considera prioritariamente a incidência do sujeito na prática analítica, e por causa disso vai refazer o desenvolvimento sobre o "vestígio”, que já tinha efetuado em seu seminário sobre $A$ identificação (cf. SAFOUAN, 2001) para nos mostrar que o sujeito apaga o vestígio, o traço unário da identificação, transformando-o em objeto a, exatamente como é o caso a propósito do olhar e da voz na escrita.

O objeto a constitui dessa maneira aquilo que Lacan denomina "os quatro apagões" por meio dos quais o sujeito pode inscrever-se" (LACAN, 1968-69, p.311). A referência ao texto de Freud intitulado "Psychologie des foules et analyse du moi" [Psicologia de grupo e análise do ego] (1921/1981) não aparece aí senão para enfatizar a identificação do sujeito ao objeto a, cujo efeito é sua própria divisão quanto a si mesmo.

Em suma, é porque o gozo não é simbolizável que continuamos a acreditar no mito do Édipo. É o que Lacan diz quando indica que Kroeber e Lévi-Strauss tinham compreendido bem isso e assim tinham deixado o gozo fora de seus sistemas. Dessa maneira podemos seguir Lacan quando propõe reconhecer a eclosão da neurose no momento em que se produz aquilo que chama de um drama na estrutura, isto é, uma positivação do gozo erótico (autoerótico e intrusivo), correlativamente a uma positivação do desejo do Outro (sua dependência).

Retorno à pulsão, nosso ponto de partida, com sua soldagem não natural a qualquer objeto que seja. R. Gary evocava muito justamente a possibilidade de morrer de sede diante de cada fonte. Retorno igualmente à cura e ao estatuto lógico do objeto a, que se deduz daí. Após esse longo rodeio, basta-nos lembrar da palavra de Freud acerca da questão da repetição, no final da cura, pela transformação da miséria neurótica em infelicidade comum. O que podemos agora traduzir pela experiência do desejo que continua sendo desejo pela insatisfação da realização do gozo e pelo saber, no final da cura, acerca da natureza constituinte dessa insatisfação. Constituinte e não contingente. Em suma, o "isto não é isso" da castração ganha em saber aquilo que perde na busca de um sempre mais de gozar.

Em suma, “a inevitável repetição é igualmente a inevitável perda” (BROCH, 1955, p.117-118) e é dessa falha do gozo que se pode deduzir o objeto a da cura, integrando-o ao desejo como causa. Em minha opinião, é o que Lacan disse, em Le sinthome, que "nós não acreditamos mais no objeto, porém constatamos 
o desejo, e dessa constatação do desejo induzimos a causa como objetivada" (LACAN, 2005, p.36).

Recebido em 10/3/2008. Aprovado em 29/3/2008.

\section{REFERÊNCIĀS}

BROCH, Herman. (1955) La mort de Virgile. Paris: Gallimard.

FREUD, Sigmund (1895/1973.) "Esquisse d'une psychologie scientifique", in La naissance de la psychanalyse. Paris: PUF.

(1921/1981) "Psychologie des foules et analyse du moi”, in Essays de psychanalyse. Paris: Payot.

GARY, Romain. (1980) La promesse de l'aube. Paris: Folio.

LACAN, Jacques (1962-1963) Le séminaire, livre 10: L’angoisse. Inédito.

. (1968-69/2006) Le séminaire, livre 16: D’un Autre à l'autre. Paris:

Seuil.

(1970) Radiophonie. Scilicet, 2/3. Paris: Seuil.

(2001) Autres écrits. Paris: Seuil.

(2005) Le sinthome. Paris: Seuil.

POÈMES EM ARCHIPEL. (2007) Anthologie de textes de René Char.

Paris: Folio.

SAFOUAN, Moustapha (2001) Dix conférences. Paris: Fayard.

(2006) L'élaboration du concept d'objet a à travers l'histoire

des théories psychanalytiques. Mensuel n.18, École de Psychanalyse des

Forums du Champ Lacanien, outubro.

Christian Hoffmann

hoffmann.ch@wanadoo.fr 